\section{References}

Allan, T. M. (1971). Personal communication.

Cammock, E. E., Hallett, W. Y., Nyhus, L. M., and Harkins, H. N. (1963). Archives of Surgery, 86, 608

Cocks, J. R., Desmond, A. M., Swynnerton, B. F., and Tanner, N. C. (1972). Gut, 13, 331 .

Coghill, N. F., and Willcox, R. G. (1960). Quarterly fournal of Medicine, 29, N.S., p. 575.

Doll, R., Jones, F. A., and Buckatzsch, M. (1951). Medical Research Council Special Report Series, No. 276. London, H.M.S.O.

Gardiner, G. C., Pinsky, W., and Myerson, R M. (1966). American fournal of Gastroenterology, 45, 22.

General Register Office, Scotland (1956). Census, 1951, vol. 4. Edinburgh, H.M.S.O. General Register Office, Scotland (1964). Census, 1961, vol. 1. Edinburgh,
H.M.S.O.

General Register Office, Scotland (1967). Sample Census, 1956. Edinburgh, H.M.S.O.

Hall, W. H., Read, R. C., Mesard, L., Lee, L. E., and Robinette, C. D. (1972). Gastroenterology, 62, 1120.
Hamilton, J. E., Harbrecht, P. J., Robbins, R. E., and Noland, J. L. (1965). Surgery, Gynecology and Obstetrics, 121, 545.

Herner, B., Kalgard, B., and Lauritzen, G. (1965). Acta Medica Scandinavica, 177, 483.

Jones, F. A. (1969). British Medical fournal, 2, 267.

Jones, P. F., Johnston, Shirley J., McEwan, A., Kyle, J., and Needham, C. D. (1973). British Medical fournal, 3, 660. Ewan, A., Johnston, Shirley

Needham, C. D., and McConachie, J. A. (1950). British Medical fournal, 2, 133.

Needham, C. D., Kyle, J., Jones, P. F., Johnston, S. J. and Kerridge, D. F. (1971). Gut, 12, 819.

Palmer, E. D. (1969). Fournal of the American Medical Association, 207, 1477. Pulvertaft, C. N. (1959). British Fournal of Preventive and Social Medicine, 13,131 . Registrar General for Scotland (1968). Annual Report for 1967. Edinburgh,
H.M.S.O.

Registrar General (1969). Statistical Review of England and Wales for 1967. London, H.M.S.O.

Schiller, K. F. R., Truelove, S. C., and Williams, D. G. (1970). British Medical fournal, $2,7$.

\title{
Further Haemorrhage after Admission to Hospital for Gastrointestinal Haemorrhage
}

\author{
PETER F. JONES, SHIRLEY J. JOHNSTON, ARTHUR B. MCEWAN, JAMES KYLE, \\ CHARLES D. NEEDHAM
}

British Medical fournal, 1973, 3, 660-664

\section{Summary}

During 1967 and 1968817 episodes of acute alimentary tract haemorrhage were treated in Aberdeen hospitals. In 229 cases further haemorrhage occurred in hospital, with a mortality of $\mathbf{2 8 . 8} \%$; the mortality among patients who did not have this complication was $7 \cdot 8 \%$. This was true of any kind of further haemorrhage. As judged by transfusion requirements and mortality the severity of the further haemorrhage was unaffected by its occurrence as haematemesis and melaena or as melaena only or by whether it took place before or after 48 hours from the time of admission. The occurrence of further haemorrhage did not appear to be affected by the sex or blood group of patients, by aspirin ingestion, or by a history of a previous haemorrhage.

The effects of the occurrence of further haemorrhage, of the age being over 60 years, or of coincidental disease being present were of descending importance in regard to mortality.

Among 151 patients with peptic ulcer and further haemorrhage half required urgent surgery and $20 \%$ died. Further haemorrhage is a dangerous condition and its occurrence should immediately signal the need for vigilance and for urgent consultation between physician and surgeon. Any delay in treatment entails increased mortality.

Foresterhill and Associated Hospitals, Aberdeen

PETER F. JONES, M.CHIR., F.R.C.s., Consultant Surgeon

JAMES KYLE, M.CH., F.R.C.S., Consultant Surgeon

CHARLES D. NEEDHAM, M.D., F.R.C.P., Consultant Physician

Gastroenterological Unit, Aberdeen Royal Infirmary, Aberdeen AB9 2ZB

SHIRLEY J. JOHNSTON, F.R.C.S., Research Registrar

St. James's Hospital, Leeds LS9 7TF

ARTHUR B. McEWAN, F.R.C.S., Senior Surgical Registrar

\section{Introduction}

Patients admitted to hospital with acute alimentary tract haemorrhage can be divided into those who show evidence of further bleeding after admission and those who do not. All published reports have shown that bleeding after admission is of grave prognostic significance; mortality has been found to be multiplied by factors of 12 (Avery Jones, 1956), 10 (Needham and McConachie, 1950), and six (Schiller et al., 1970) among patients with further bleeding in hospital. Further haemorrhage is easy to recognize when a patient repeatedly vomits blood. However, only two-thirds of the group do this; the remainder have melaena only or bleed internally. The objects of this paper are to examine the problems presented by further haemorrhage occurring in hospital and to study the behaviour and response to treatment of patients who suffer this complication.

The term further haemorrhage (F.H.) has been adopted because it can include both true recurrent bleeding and bleeding that has continued from the time of admission. Patients who were admitted to hospital having had haematemesis or melaena were considered to have suffered F.H. when (1) in spite of adequate resuscitation the patient continued to show signs of blood loss requiring further transfusion, with (or occasionally without) further haematemesis or melaena, or (2) after an interval during which the patient showed no signs of internal bleeding there was $(a)$ vomiting or nasogastric aspiration of freshly-shed blood or $(b)$ renewed evidence of hypovolaemic shock or rapidly progressive anaemia.

Melaena alone was not accepted as evidence of F.H. because it is not possible to distinguish blood shed before admission from that due to more recent haemorrhage.

\section{Method}

All patients over 12 years of age in the Aberdeen hospitals during 1967 and 1968 who had haematemesis or melaena were interviewed and detailed contemporary records were made. A total of 795 patients suffered 817 episodes of bleeding (Johnston et al., 1973). Altogether 192 patients suffered F.H. after being admitted for either haematemesis or melaena or both. Among 74 patients who were already in hospital for other reasons when they first showed alimentary bleeding there were 37 who had 
TABLE I-Occurrence of Further Haemorrhage in 817 Cases of Haematemesis or Melaena or Both

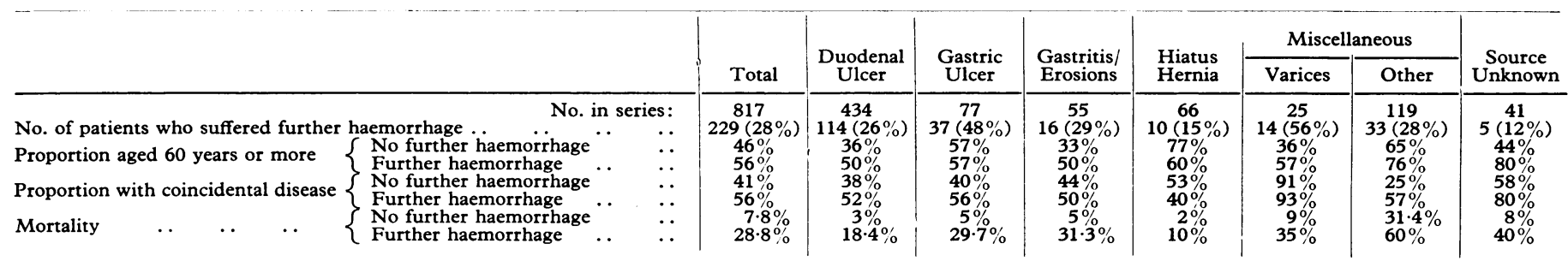

F.H. after the initial episode. Thus 229 episodes of F.H. were available for study.

\section{Results}

The diagnostic groupings of the 817 cases in the main survey and the numbers in which F.H. occurred are shown in table I. This table also compares three features of the patients who did and did not have F.H.-(1) the percentage aged 60 years or over; (2) the percentage with coincidental, unrelated disease; and (3) the mortality rates.

Further analysis of the F.H. group showed that (4) males and females were equally prone to F.H. in all diagnostic groups. (5) Blood group $\mathrm{O}$ occurs in $50 \%$ of the local population (Allan,
1972); among those in the survey with peptic ulcer but without F.H. the incidence was $56 \%$ but with F.H. it was $63 \%$. The incidence of group $\mathrm{O}$ was also high in the gastritis group but in the other categories it matched that found in the control population. (6) Aspirin had been ingested within 72 hours of admission by $26 \%$ of those with F.H. compared with $25 \%$ of those without F.H. (7) Coincidental disease was present with equal frequency among those who developed F.H. and those who did not. (8) Admission to hospital within 24 hours of onset of bleeding took place equally often among those who did and those who did not suffer F.H. (9) $A$ history of previous alimentary haemorrhage was obtained from $37 \%$ of those who had F.H. and from $35 \%$ of those with no F.H. (10) Previous surgery for bleeding had been performed on only two of the 229 patients with F.H., and on both occasions this was for duodenal ulcer. (11) Among 74

FIG. 1-Type of initial presentation and of recurrence of gastrointestinal haemorrhage, and outcome. 
patients already in hospital when they first bled $51 \%$ of the 37 who suffered F.H. and $38 \%$ of the 37 who did not suffer F.H. died. The respective comparable mortality figures for those admitted because of bleeding were $24 \%$ and $5 \cdot 8 \%$.

\section{OCCURRENCE AND FORM OF F.H.}

In the whole series of 817 bleeding episodes 583 cases presented with haematemesis, and of these $176(30 \%)$ had F.H. Among 234 cases of melaena $53(22.6 \%)$ had F.H. Seventy-seven per cent. of all episodes of F.H. occurred after initial haematemesis and $23 \%$ after initial melaena. F.H. may occur as either haematemesis or melaena or internal bleeding and often does not take the same form as the initial haemorrhage (fig. 1). Also mortality was not related to the form of the initial or further haemorrhage (fig. 1). F.H. occurred as melaena in almost one-third of all instances (table II), and these patients required just as much blood as did those with F.H. in the form of haematemesis; mortality, however, was slightly less in the melaena group.

\section{TIMING}

In four out of five patients with F.H. bleeding occurred within 48 hours of admission or of the initial bleed and these are termed
TABLE II-Type of Further Haemorrhage

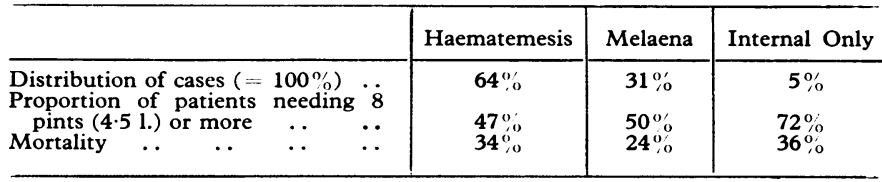

TABLE III-Timing of Further Haemorrhage

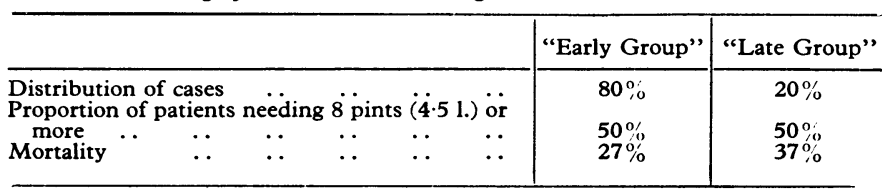

the "early" group. The $20 \%$ whose F.H. was delayed more than 48 hours are termed the "late" group. These late bleeders required equally large transfusions and suffered a higher mortality than did the early group (table III). Analysis shows that the early or late timing of F.H. was not related to whether the initial bleed or the F.H. occurred as haematemesis or melaena. 


\section{F.H. IN PATIENTS WITH PEPTIC ULCER}

Among all 817 episodes 434 patients were found to have a duodenal ulcer and 77 a gastric ulcer (including 13 who also had a duodenal ulcer). This "ulcer" group (totalling 511 patients) was the largest in the survey and has been further examined because it is more homogeneous than the other diagnostic groups and is of much practical significance. The behaviour of the 511 patients is shown in fig. 2 . During the first 24 hours in hospital 106 patients continued to bleed but 405 showed no sign of F.H. Among these 405, however, 45 subsequently showed signs of F.H., so that the total number of peptic ulcer patients with F.H. was 151. Fig. 2 shows how at all times liability to F.H. in these patients is unpredictable.

Forty-eight per cent. of the patients with gastric ulcer suffered F.H. compared with $26 \%$ of those with duodenal ulcer and of those with F.H. $29.7 \%$ of the gastric ulcer patients died compared with $18.4 \%$ of the duodenal ulcer group (table I). The gastric ulcer patients were older than the patients with duodenal ulcer $(57 \%$ as opposed to $50 \%$ respectively were more than 60 years old) and they had a slightly higher incidence of coincidental disease ( $56 \%$ with $52 \%$ ).

Blood transfusion requirements after F.H. were large. Among 114 patients with duodenal ulcer one-half needed 8 or more units and one-quarter needed 12 or more.

Of the 151 patients with F.H. $75(50 \%)$ required urgent surgery. Fifty-three had a duodenal ulcer and 22 a gastric ulcer. Forty underwent a Polya gastrectomy, 11 a Billroth I gastrectomy, 17 vagotomy with drainage and suture of the bleeding point, 3 pyloroplasty only (in one case with suture of a perforation), and 4 had other operations. There were 18 operative deaths $(24 \%)$, one of which occurred among the 17 patients having vagotomy with drainage and suture and 15 occurred among the 51 having partial gastrectomy. Of these 15 deaths 4 were due to surgical complications and the other 11 were due to pulmonary embolism (3), cerebrovascular accidents (2), continued bleeding after massive transfusion (2), pancreatitis (1), coronary thrombosis (1), respiratory infection (1), and cardiac arrest en route to the theatre (1). Two patients died after local excision of a gastric ulcer; in one the ulcer had developed in a thoracic stomach five years after excision of carcinoma oesophagus, and the other was in a chronic psychotic patient who developed both perforation and bleeding.

Mortality was disturbingly high at all stages of management. The three factors that seemed particularly worthy of analysis were (1) the occurrence of F.H., (2) age over 60 years, and (3) the presence of coincidental disease. The results of variance analysis of the whole peptic ulcer group (511 patients) and of the group split into those with (151) and without F.H. (360) are given in tables IV and V. It is apparent that the type of bleed, an age over 60 years, and the presence of coincidental disease are of descending importance in regard to mortality. Table $\mathrm{V}$ shows

TABLE IV-Analysis of Variance (using Arcsin Transformation) for All (511) Peptic Ulcer Group

\begin{tabular}{|c|c|c|c|}
\hline Source of Variation & $\begin{array}{c}\text { Degrees of } \\
\text { Freedom }\end{array}$ & $\begin{array}{c}\text { Variance } \\
\text { Estate }\end{array}$ & Significance \\
\hline $\begin{array}{l}\text { Type of further haemorrhage } \\
\text { Age } \geqslant 60 \text { years } \\
\text { Coincidental disease }\end{array}$ & $\begin{array}{l}1 \\
1 \\
1 \\
4\end{array}$ & $\begin{array}{r}670 \\
364 \\
70 \\
19\end{array}$ & $\begin{array}{c}\mathbf{P}<0.01 \\
\mathbf{P}<0.025 \\
\text { N.S. }\end{array}$ \\
\hline
\end{tabular}

TABLE v-Analysis of Variance (using Arcsin Transformation) for Patients with Peptic Ulcer either having or not having Further Haemorrhage

\begin{tabular}{|c|c|c|c|c|}
\hline \multirow[b]{2}{*}{ Source of Variation } & \multicolumn{2}{|c|}{$\begin{array}{l}\text { No Further Haemorrhage } \\
(\mathrm{n}=360)\end{array}$} & \multicolumn{2}{|c|}{$\begin{array}{l}\text { Further Haemorrhage } \\
\qquad(\mathrm{n}=151)\end{array}$} \\
\hline & $\begin{array}{l}\text { Degrees of } \\
\text { Freedom }\end{array}$ & $\begin{array}{l}\text { Variance } \\
\text { Estimate }\end{array}$ & $\begin{array}{l}\text { Degrees of } \\
\text { Freedom }\end{array}$ & $\begin{array}{l}\text { Variance } \\
\text { Estimate }\end{array}$ \\
\hline $\begin{array}{ll}\text { Age } \geqslant 60 \text { years } & \\
\text { Coincidental disease } & \ldots \\
\text { Residual } & \ldots\end{array}$ & $\begin{array}{l}1 \\
1 \\
1\end{array}$ & $\begin{array}{r}293.44 \\
1.04 \\
1.05\end{array}$ & $\begin{array}{l}1 \\
1 \\
1\end{array}$ & $\begin{array}{r}93.61 \\
113.96 \\
\text { Nil }\end{array}$ \\
\hline
\end{tabular}

that age had a relatively important effect on the outcome for both non-F.H. and F.H. patients, while the presence of coincidental disease was of importance only among those suffering F.H.

As soon as F.H. occurred mortality rose sharply and was greater with a later onset. Thus the mortality was $18 \%$ among the 106 who continued bleeding in the first 24 hours but $29 \%$ when recurrence was delayed until after 24 hours from admission. Thirty-two of the 151 patients in the peptic ulcer F.H. group died. In 23 death was almost certainly inevitable. Most of these patients were old and frail and many had other serious disease. Nine were already in hospital when they bled and in seven the haemorrhage was not a major factor in causing death. A further 14 patients admitted for bleeding died of severe intercurrent disease. The average age of this group of 23 patients was 71 years. In the remaining nine patients it is possible that modification of treatment might have been beneficial, though it is easier to see this in retrospect. Among the four surgical deaths (two patients continued to bleed, two leaked from the duodenum) three patients were operated on after transfusion of 13 or more units of blood and operation took place at night, in two cases after 1 a.m. The other five patients had all continued to bleed over some days and were maintained for various reasons on a medical regimen; they then had to come to surgery and died of medical complications such as pulmonary embolism or respiratory failure.

In the gastritis group 16 patients had F.H. and six required urgent operation-four had an erosion underrun, one had a successful vagotomy and pyloroplasty for multiple bleeding punctate erosions, and one had a gastrotomy only. Among the 10 patients with a hiatus hernia and F.H. one required an emergency oesophagogastrectomy and one had a vagotomy and pyloroplasty with repair of the hiatus hernia. All these eight patients who had operations survived.

\section{Discussion}

The outstanding finding in this survey is that once a patient has shown evidence of further bleeding, no matter whether it is manifested as haematemesis, melaena, or only internal bleeding, he has entered a category of patients who are highly likely to require surgery and who have a substantial mortality. The timing and pattern of bleeding, the age of the patient, and the presence or absence of coincidental disease are all of minor importance compared with the fact that further bleeding has taken place after admission to hospital (tables IV and V). This serious situation faced $20 \%$ of all the patients in the series and $25.8 \%$ of 511 patients in the peptic ulcer group. These proportions are very similar to those reported by Jones (1956) in 1,414 admissions and Ward-McQuaid et al. (1960) in 400 admissions for bleeding peptic ulcer. This group is therefore both numerous and dangerous.

Northfield (1971) did not consider that F.H. manifested as melaena was significant and suggested that once 48 hours had elapsed F.H. was unlikely to occur. The data in the present prospective survey give no support to these statements (fig. 1). Indeed, $31 \%$ of all cases of F.H. presented as melaena only, and these patients required as much blood and suffered nearly as high a mortality as did patients whose F.H. occurred as haematemesis (table II), a point confirmed by Nielsen and Amdrup (1969). Delay of more than 48 hours before F.H. (late group) was distinctly unfavourable to the $20 \%$ of patients in whom it occurred; in fact, they required as much blood as did the "early" group and suffered a mortality of $37 \%$, compared with $27 \%$ among those whose F.H. occurred within 48 hours (table III).

Age had its expected effect on mortality but the presence of coincidental associated disease was not significant among those who did not have F.H. and was of only minor significance among those who did; this finding is at variance with some commonly held opinions (Cammock et al., 1963; Andersen et al., 1968). At the time of admission it is not easy to identify the group of 
patients especially liable to F.H. Those who have gastric ulcer or oesophageal varices are at greater risk than the other groups (table I) but the diagnosis may not be known.

It is well known that the risks of serious complications and death are greater in gastric than in duodenal ulcer. The incidence of F.H. in gastric ulcer was almost double that in duodenal ulcer, with a mortality of $29.7 \%$ compared with $18.4 \%$; even when F.H. did not occur the mortality in the gastric ulcer group was nearly double that in the duodenal ulcer group.

Among patients with peptic ulcer there were 12 deaths in the 360 patients without F.H. $(3 \cdot 3 \%)$ mortality. As soon as F.H. occurred mortality rose to $21 \%$ overall and was greater with increasing delay in the onset of F.H. (table III). In those who continued to bleed after 24 hours or whose bleeding first recurred after 24 hours urgent surgery became necessary in $66 \%$. There are therefore very good grounds for believing that 24 hours after admission is a time at which crucial decisions must be taken, if they have not become necessary sooner. Early consultation between physician and surgeon is essential in every case of F.H. The physician must resist the temptation to carry on and not bother his colleague until operation is imperative because this can lead to the surgeon being asked late in the evening to see a patient who has already received 12 or more units of blood. By this time other emergencies are likely to be waiting their turn for the theatre, and these are just the circumstances in which misjudgements can occur.

Immediate joint consultation does not necessarily mean immediate operation but enables the surgeon to meet the patient, assess the situation, and plan his work. Nothing is gained by delaying surgical consultation. At this point the surgeon will naturally want to know the source of bleeding, and it is here that fibreoptic endoscopy is making a substantial contribution. Palmer (1969), reporting on the investigation of 1,400 patients within a few hours of admission for bleeding, found that the crucial investigation in identifying the source of bleeding was oesophagoscopy in $26 \%$, gastroscopy in $33 \%$, and radiology in $33.4 \%$. Endoscopy is the only way in which the surgeon can positively know the source of bleeding before operation, and this may influence the decision to operate.

Delay is particularly undesirable in the presence of chronic peptic ulceration. Finsterer (1939) was emphatic that operation should not be delayed more than 48 hours because of the immediate danger of F.H. Harvey and Langman (1970) also showed how these patients if treated medically continue over the years to have a cumulative relapse rate which is far higher than in patients who are operated on at the time of bleeding.

There is a strong temptation to delay the decision to operate in patirnts who through age or severe coincidental disease are poor surgical risks. These risks, however, do not diminish as the days pass and bleeding waxes and wanes, even though the loss is made good by blood transfusion. This was confirmed by Cocks et al. (1972), who had an operative mortality of $14 \%$ for the day of admission, $33 \%$ on the fourth day, and $52 \%$ for the seventh day after admission.

Delay may also occur because the patient has no past dyspeptic history. That this happens is suggested by the higher mortality in this group (Johnston et al., 1973); it is important not to allow the absence of history to exert undue influence.

The most important fact to remember about F.H. is that once it has happened it is irrelevant to debate whether the bleeding has stopped or is continuing. It is the first indication of F.H. which is the danger signal indicating that the patient has entered this high-risk group (Needham and McConachie, 1950).

It is necessary to consider whether the common use of partial gastrectomy in this series contributed to the high mortality.
Foster et al. (1965) put forward strong evidence that vagotomy, pyloroplasty, and underrunning of the bleeding point in the ulcer is the safest way of controlling haemorrhage from a chronic duodenal ulcer in the poor-risk patient. The results of this operation in this survey support this view and correspond with our own experience and that of many others. It is of interest, however, that Schiller et al. (1970) found that partial gastrectomy was a little safer than vagotomy and drainage among younger patients, so this debate remains open. Emergency partial gastrectomy for bleeding is likely to be technically difficult and its use should be confined to those with a wide experience of elective gastrectomy.

Cocks et al. (1972), who reported a mortality of $17 \%$ in 367 emergency gastrectomies, concluded that it is difficult to make comparisons between the mortality rates of different hospitals. It is therefore interesting to find that although various operative procedures were employed and the use of emergency surgery varied between $12.7 \%$ and $28.5 \%$ the overall mortality rates for bleeding gastroduodenal ulceration were $8.6 \%$ and $8.9 \%$ in the two large series reported by Schiller et al. (1970) in Oxford and Cocks et al. (1972) in London and $8.6 \%$ in the present survey.

\section{Conclusion}

The patient who is admitted for acute gastrointestinal bleeding and who has further haemorrhage after admission faces an even chance of losing 8 or more pints $(4.51$.) of blood. If bleeding comes from a peptic ulcer half the patients will require urgent surgery, and if bleeding recurs after 24 hours or continues for more than this period two-thirds will need urgent surgery and one in four is liable to die. Procrastination carries a heavy penalty; the first sign of F.H. is a signal for consultation between experienced medical and surgical colleagues. If immediate operation is not advised regular consultation and close observation must continue because the threat of F.H. persists for some days.

We thank all of our medical and surgical colleagues who allowed us free access to patients under their care. We wish to thank Miss Ianthe Dingwall-Fordyce for carrying out the variance analysis of factors influencing mortality. Grateful acknowledgement is made to the North-Eastern Regional Hospital Board (Scotland), who financed the survey. We are indebted to our secretaries Mrs. C. Smith and Mrs. J. Amonoo for much patient help throughout the work.

\section{References}

Allan, T. (1972). Personal communication.

Andersen, D., Klebe, J. G., and Nielsen, A. (1968). Scandinavian fournal of Gastroenterology, 3, 537. Cammock, E. E., Hallett, W. Y., Nyhus, L. M., and Harkins, H. N. (1963).
Archives of Surgery, 86, 608.

Cocks, J. R., Desmond, A. M., Swynnerton, B. F., and Tanner, N. C. (1972). Gut, 13, 331.

Finsterer, H. (1939). Surgery, Gynecology and Obstetrics, 69, 291.

Foster, J. H., Hickok, D. F., and Dunphy, J. E. (1965). Annals of Surgery,

161, 968.
Harvey, R. F., and Langman, M. J. S. (1970). Quarterly Journal of Medicine,

39, N.S., p. 539.
Johnston, S. J., Jones, P. F., Kyle, J., and Needham, C. D. (1973). British Medical fournal, 3, 655 .

Jones, F. A. (1956). Gastroenterology, 30, 166.

Needham, C. D., and McConachie, J. A. (1950). British Medical fournal, 2, 133.

Nielsen, S. P., and Amdrup, E. (1969). Acta Chirurgica Scandinavica, 396, Suppl., p. 29.

Northfield, T. C. (1971). British Medical fournal, 1, 26.

Palmer, E. D. (1969). Fournal of the American Medical Association, 207, 1477. Schiller, K. F. R., Truelove, S. C., and Williams, D. G. (1970). British Medical Fournal, 2, 7.

Ward-McQuaid, J. N., Pearse, J. C., Smith, A. McE., and Twort, R. J. (1960). Gut, 1, 258. 